\title{
Revista del Instituto Nacional de Cancerología: pasado, presente $y$ futuro
}

La revista del Instituto Nacional de Cancerología hizo su aparición por vez primera en el año 1954. Como posiblemente sucede con otras publicaciones, la revista se enfrentó a un sinnúmero de problemas para su publicación, por lo que aparecía un solo número al año. En 1985 fui designado editor y junto al impresor decidí un cambio de fondo y forma, busqué el apoyo financiero con los laboratorios y elegí un Comité Editorial incluyendo prestigiosos oncólogos nacionales, latinoamericanos y oncólogos de habla hispana residentes en Estados Unidos. Con esta nueva estructura apareció el volumen 31, número 1-2, en marzo de 1985, con artículos de interés en la especialidad de diferentes instituciones oncológicas de México. Posteriormente nos vimos enriquecidos con numerosas aportaciones de instituciones oncológicas de Centroamérica y Sudamérica, incluyendo de EE. UU. y de Europa. La American Society of Clinical Oncology (ASCO) autorizó la publicación en castellano de sus mejores resúmenes y los de interés para nuestros países.

En 1993 al ser nombrado director general del Instituto Nacional de Cancerología invité al doctor Alejandro Mohar Betancourt, editor asociado, para hacerse cargo de la revista como editor de la misma. El doctor Mohar es el director de investigación en nuestro Instituto. Escribí en el volumen 39, número 4, de octubre-diciembre de 1993, una semblanza editorial como editor en jefe de la revista. En el análisis de esos 9 años como responsable de dar vida a la revista del Instituto Nacional de Cancerología mencioné que la revista estaba ya reconocida y aceptada por varias organizaciones como Excerpta Médica, Index Medicus Latinoamericano, Cenids y además había sido incluida en el CD- ROM Artemisa.

Asimismo contaba con más de 800 suscripciones, el material publicado contenía trabajos de médicos oncólogos de México, América Latina, Europa, África, Estados Unidos y Canadá. Quedaba en trámite su inclusión en índices internacionales como el Index Medicus y Current Contents, quienes nos solicitaron más años de publicación continua y regularidad para incluir en sus índices a la revista; ambas condiciones se han cumplido.

Mencioné también que llegaba el momento de entregar la estafeta de la revista a un médico como Alejandro Mohar Betancourt, de quien tenía la firme convicción de que conseguiría que la revista no sólo continuase con el mismo nivel alcanzado, sino que la conduciría a uno excelente. Hoy me es muy satisfactorio confirmar que gracias a la labor desempeñada, la revista fue re-

Rev Oncología 2001;3: 1-2 conocida por el Consejo Nacional de Ciencia y Tecnología (CONACYT) de México como una de las mejores revistas médicas nacionales. Fue aceptada en el índice de revistas científicas de nuestro país y se le otorgó apoyo económico para consolidar este nuevo proyecto con la Federación de Sociedades Españolas de Oncología (FESEO).

Nuestra revista cuenta hasta el momento con más de 1.200 suscripciones y con una antigüedad de 15 años ininterrumpidos. De acuerdo a una encuesta reciente de Internet de la revista del INCan, ocupa el primer lugar en consultas para revistas en castellano de publicación trimestral. Se considera que es la revista oncológica más conocida y leída por oncólogos mexicanos y latinoamericanos.

Actualmente la revista es el órgano oficial del Instituto Nacional de Cancerología, Sociedad Mexicana de Estudios Oncológicos, Grupo de estudio y tratamiento Latinoamericano del Cáncer, Asociación Latinoamericana de Institutos contra el Cáncer, Unión Internacional contra el Cáncer, Federación Latinoamericana de Sociedades contra el Cáncer, Círculo de Radioterapeutas Oncólogos Ibero Latinoamericano y Asociación Mexicana de Onco-Hematología Pediátrica.

Para el año 2001 hemos firmado un convenio con la revista española Revista de Oncología, órgano oficial de la Federación de Sociedades Españolas de Oncología (FESEO), la revista oncológica de mayor circulación en España y América Latina.

Con este número se abre un nuevo capítulo en la ya larga relación de 2 países hermanos. México es un buen ejemplo de un país en transición epidemiológica, donde coexisten enfermedades crónicas degenerativas y enfermedades transmisibles como las principales causas de muerte. A partir de 1990 las enfermedades neoplásicas malignas ocupan el segundo lugar en cuanto a mortalidad, con más de 50.000 fallecimientos anuales. $\mathrm{Al}$ año se registran más de 85.000 nuevos casos de cáncer. En mujeres el cáncer de cérvix uterino es el tumor más frecuente, seguido de el de mama, ovario, endometrio y estómago; en hombres, cáncer de próstata, pulmón, estómago, linfoma no Hodgkin y colon/recto son los más frecuentes.

Dada la mejoría de las condiciones de Atención Primaria para la salud y el envejecimiento de nuestra población, el cáncer se ha convertido en un grave problema de salud pública en México. Es indispensable desarrollar una estrategia nacional global para afrontar esta emergente demanda de atención médica por el paciente oncológico.

Esta fusión de revistas es un paso en esa dirección. Con ello podremos abrir la discusión a nuevas ideas, 
proyectos y colaboraciones. Duplicaremos la tirada, la difusión y la transición hacia el idioma inglés. Como se puede apreciar, el Comité Editorial está compuesto por un grupo interdisciplinario e internacional de investigadores sobre el cáncer. Tenemos la certeza de que todo este esfuerzo tendrá como resultado la mejora de la calidad e impacto de nuestras publicaciones y brindará un importante apoyo para optimizar la atención médica al paciente oncológico.

Es importante señalar que éstos han sido los pasos iniciales de un largo camino. El principio ha sido fácil, ya que ambos editores, así como miembros de la FESEO y del INCan, tenemos la certeza de que nuestra realidad obliga a reunir esfuerzos, talentos y trabajo. Sin em- bargo, también sabemos que satisfacer todas las expectativas y objetivos de este proyecto requerirá mucho trabajo y compromiso por las 2 partes.

Así pues, la Revista de Oncología (España) y la $R e$ vista de Cancerología (México) se fusionan en una sola revista con el único y firme propósito de tener una mayor cobertura, invitar a todos los oncólogos de habla hispana a publicar sus trabajos en el idioma inglés en una revista de alta calidad y alcanzar un mayor reconocimiento dentro de la comunidad científica internacional.

Jaime de la Garza Salazar Instituto Nacional de Cancerología. 